\title{
Capital espacial entre los trabajadores agrícolas mexicanos en contextos de trabajo no libre en Canadá
}

\section{Spatial capital among Mexican agricultural workers in contexts of unfree labour in Canada}

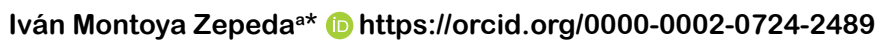

Recibido el 22 de junio de 2020.

Aceptado el 11 de diciembre de 2020.

Publicado el 17 de diciembre de 2020.

*Autor para correspondencia: Iván Montoya Zepeda. Correo electrónico: imz@azc.uam.mx

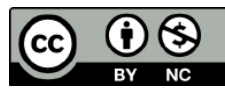

Esta obra está protegida bajo una Licencia Creative Commons Atribución-NoComercial 4.0 Internacional.

\begin{abstract}
a Universidad Autónoma Metropolitana, Unidad Azcapotzalco, Departamento de Sociología, Ciudad de México, México, correo electrónico: imz@azc.uam.mx
\end{abstract}

\section{Resumen}

En el artículo se examina el capital espacial adquirido por los trabajadores agrícolas mexicanos en Canadá como un activo que puede brindarles un poder o una influencia en contextos de trabajo no libre. Se propone pensar el mercado laboral agrícola como un campo bourdiano. Se recurre a un enfoque cualitativo, apoyado en cinco entrevistas individuales y dos colectivas efectuadas en 2011 en granjas y espacios públicos en la zona periférica de la Región de Montreal, Quebec. Fragmentos de las entrevistas permiten observar el espacio como sitio de conflicto y como un tipo de capital que confiere a los trabajadores la capacidad de agencia para enfrentarse a las relaciones de dominación y subordinación del "campo del trabajo temporal agrícola migrante en Canadá", así como al aislamiento y exclusión socioespacial. También se observan otras formas de capital como el lingüístico y el social, los cuales permiten generar y elevar el capital espacial.

Palabras clave: agencia, campo, ciudadanía, migración laboral, trabajo no libre.

\begin{abstract}
The article examines the spatial capital acquired by Mexican agricultural workers in Canada as an asset that can give them power of influence in contexts of unfree labour. It proposes to think about agricultural labour markets as fields, after Bourdieu. A qualitative approach is used, and the text is based on five individual and two collective interviews conducted in 2011 on farms and in public spaces in the peripheral area of the Montreal Region, Quebec. Fragments of the interviews allow us to observe the space as a site of conflict and as a capital that gives workers the capacity for agency which allows them to confront relations of domination and subordination in the "field of migrant agricultural seasonal work in Canada", and
\end{abstract}


to confront socio-spatial isolation and exclusion. Other forms of capital are also observed, such as linguistic and social, which allow spatial capital to be to generate and increased.

Keywords: agency, field, citizenship, labour migration, unfree labour.

\section{Introducción}

Para este trabajo se toman en consideración dos características del espacio, por un lado, el lugar de competencia, conflicto y arena de lucha y, por el otro, el recurso para ejercer una influencia de acuerdo con los intereses de los agentes. Se utiliza la categoría de capital de Bourdieu para proponer la noción de capital espacial como uno de varios activos que pueden utilizar los trabajadores agrícolas mexicanos para incrementar su capacidad de agencia, resistir a las relaciones de poder y lograr una mejor posición dentro del campo del trabajo temporal agrícola migrante en Canadá.

La estructura del Programa de Trabajadores Agrícolas Temporales entre México y Canadá (PTAT) $)^{1}$ favorece las restricciones de movilidad y el aislamiento socioespacial en contextos de trabajo no libre. Por ello, el capital espacial puede ayudar a los trabajadores a usar y apropiarse del espacio, lo que contribuye a disminuir el aislamiento y conquistar inclusión socioespacial en la sociedad canadiense.

Canadá es una sociedad moderna e industrializada, donde el ejercicio pleno de los derechos ciudadanos está garantizado por su Constitución política, por la Carta Canadiense de los Derechos y las Libertades y por pactos y declaraciones internacionales sobre derechos humanos. Discursivamente, sus programas de trabajo de baja calificación garantizan los derechos de los trabajadores temporales. El contrato del PTAT representa, formalmente, un ejercicio del derecho civil, un convenio para efectuar un trabajo libre.

Sin embargo, en estas sociedades modernas aparece una contradicción entre las fuerzas igualitarias de la ciudadanía social y la desigualdad del sistema de producción capitalista, que, en su expansión y desarrollo, se apoya en prácticas de trabajo no libre. Por lo anterior, aunque el contrato entre el trabajador y el empleador es celebrado legalmente entre personas libres e iguales, en la práctica una parte de esta relación no lo es, pues tan solo el estatus legal ciudadano de los empleadores y el estatus legal temporal de los trabajadores migrantes los vuelve desiguales en sus dotaciones de poder.

En este sentido, la estructura y operación del PTAT representan un dispositivo de poder que tiene consecuencias socioespaciales para los trabajadores agrícolas mexicanos; obstaculiza el ejercicio de los derechos ciudadanos; les impide el acceso a la educación, a la residencia permanente, a la movilidad en el mercado laboral; experimentan dificultades para acceder a los servicios de salud y compensaciones económicas; los aísla geográficamente; y, los excluye socialmente de la participación comunitaria en Canadá (Basok et al., 2012; Cohen, 2019; Cohen \& Caxaj, 2018; Hennebry \& Preibisch, 2010; Perry, 2018, 2019) produciendo contextos de trabajo no libre.

Para que el capital espacial se ligue con otras formas de capital eficiente, se retoma la definición de campo de Pierre Bourdieu y se propone concebir el circuito migratorio y laboral agrícola entre Canadá y México bajo ese esquema. De este modo, se pueden

${ }^{1}$ El programa cumplió 46 años de operación en 2020. Se conoce en inglés como Seasonal Agricultural Worker Programa (SAWP) y en francés como Programme du Trabajeur Agricole Seasonale (PTAS). 
distinguir, por ejemplo, el capital lingüístico, el jurídico y el social que, intercambiados o combinados, pueden brindar a los trabajadores capacidades diferenciadas para actuar, posicionarse, resistir y obtener alguna ventaja en las relaciones de poder producidas en este espacio social.

Para entender cómo opera el capital espacial a favor de los trabajadores agrícolas mexicanos se presentan extractos seleccionados de cinco entrevistas individuales y dos colectivas, efectuadas en las residencias temporales de los trabajadores y en algunos espacios públicos de la provincia de Quebec, Canadá. La ficha básica de información de estos entrevistados se puede consultar en la Tabla 1. Tales entrevistas son parte del trabajo de campo desarrollado entre marzo y agosto de 2011, en dicha provincia.

Tabla 1: Ficha básica de los entrevistados en Quebec, Canadá

\begin{tabular}{|c|c|c|c|c|c|}
\hline Entrevistado & $\begin{array}{c}\text { Edad } \\
\text { en } 2011\end{array}$ & $\begin{array}{l}\text { Origen en } \\
\text { México }\end{array}$ & $\begin{array}{r}\text { Temporadas } \\
\text { hasta el } 2011\end{array}$ & $\begin{array}{c}\text { Municipio de } \\
\text { la granja }\end{array}$ & Tipo de granja \\
\hline David & 43 & $\begin{array}{l}\text { Estado de } \\
\text { México }\end{array}$ & 14 & Laval & $\begin{array}{l}\text { Repollo, lechuga, } \\
\text { cebolla, pepinillo }\end{array}$ \\
\hline Fernando & 38 & Morelos & 13 & Saint-Rémi & Repollo y nabo \\
\hline Jorge & 41 & $\begin{array}{l}\text { Estado de } \\
\text { México }\end{array}$ & 11 & Saint-Eustache & Invernadero de flores \\
\hline Rogelio & 44 & Tabasco & 10 & $\begin{array}{l}\text { Saint-Patrice- } \\
\text { de-Sher- } \\
\text { rington }\end{array}$ & Zanahoria y cebolla \\
\hline Patricio & 46 & Querétaro & 9 & Mirabel & Invernadero de flores \\
\hline $\begin{array}{c}\text { Zenen, } \\
\text { Entrevista } \\
\text { colectiva } 2\end{array}$ & 36 & Morelos & 7 & Saint-Rémi & Repollo y nabo \\
\hline $\begin{array}{c}\text { Entrevista } \\
\text { Colectiva 1, } \\
\text { cuatro traba- } \\
\text { jadores }\end{array}$ & & & & Mirabel & Invernadero de flores \\
\hline $\begin{array}{c}\text { Entrevista } \\
\text { Colectiva 2, } \\
\text { tres traba- } \\
\text { jadores }\end{array}$ & & & & Saint-Rémi & Repollo y nabo \\
\hline
\end{tabular}

Fuente: trabajo de campo 2011.

Para este artículo, las entrevistas seleccionadas tuvieron lugar en cinco municipios, los cuales se aprecian en el mapa de la Figura 1. La entrevista a David se efectuó en Laval, en su residencia temporal y en una cafetería, él labora en una finca de vegetales. Laval tiene estatus de ciudad, pero tiene zonas rurales y se encuentra al norte de Montreal.

La entrevista con Jorge se hizo en Saint-Eustache, en su residencia y en el invernadero de flores en donde laboraba. Saint-Eustache es también una ciudad con zonas rurales, se localiza al noroeste de Montreal, cruzando el río Mil Islas. Una tercera conversación ocurrió con Patricio, en Mirabel, en su residencia temporal, él trabajaba en un invernadero de flores. En la misma finca se llevó a cabo la entrevista colectiva 1. Mirabel 
está designada como ciudad y también tiene una amplia zona rural, se encuentra al noroeste de Montreal. Estos tres municipios forman parte de los 82 que constituyen la Comunidad Metropolitana de Montreal (смм).

La cuarta entrevista fue a Fernando, trabajador de una granja de vegetales en la ciudad de Saint-Rémi, sucedió en su residencia. La entrevista colectiva 2, también se realizó con compañeros de su granja, en la que participó Zenen. La quinta entrevista individual tuvo lugar en distintos restaurantes y fue concedida por Rogelio, jornalero en una finca de vegetales, en el municipio de Saint-Patrice-de-Sherrington. Estos dos últimos municipios están al sur de la CMM, pero no pertenecen a esta. Saint-Patrice limita con Estados Unidos.

Figura 1: Mapa de la provincia de Quebec, municipios de las entrevistas seleccionadas

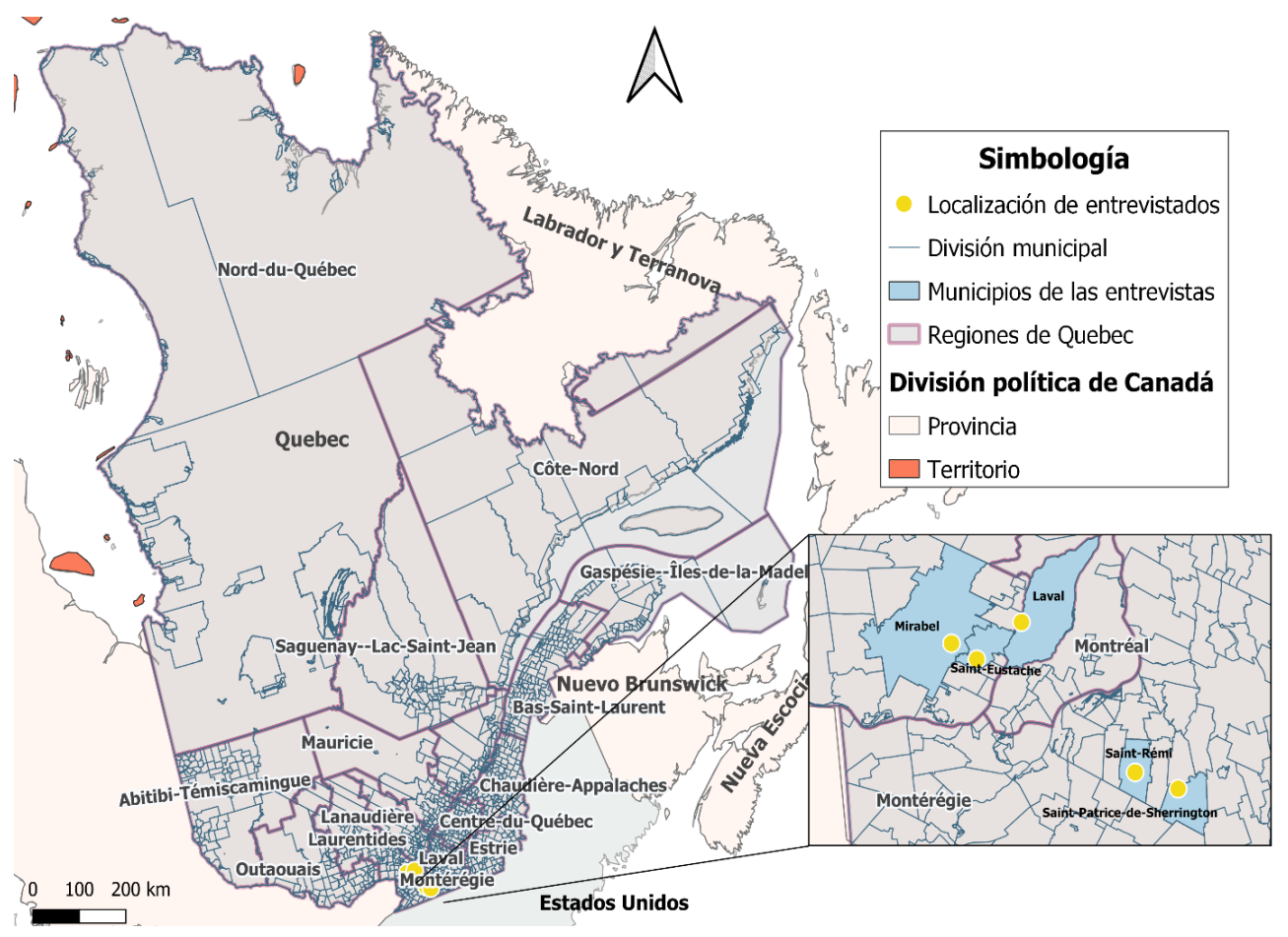

Fuente: elaboración propia con datos de https://mern.gouv.qc.ca/ministere/cartes-informationgeographique/

Cabe agregar que, en términos del número de trabajadores agrícolas mexicanos contratados por provincia, Ontario ha sido la que más mano de obra ha solicitado. Sin embargo, al poner atención en la Tabla 2, se aprecia que, en los últimos 10 años, han ocurrido algunos cambios en las cifras relativas. Por ejemplo, en 2010, Ontario contrataba a poco más de 50\% de los jornaleros del Programa, y Quebec y Columbia Británica se mantenían en el segundo puesto con una quinta parte de los contratos, respectivamente. Luego, en 2019, el peso relativo de las contrataciones en Ontario bajó a 42.9\%, mientras que la provincia de Quebec se ubicó en segundo lugar con $24 \%$, casi un cuarto de las colocaciones y, además, duplicó las cifras absolutas, pasando de 3085 a 6 333, en nueve años. Columbia Británica quedó en tercer lugar, aunque 
muy próxima a Quebec, con un peso relativo, en 2019, de 22.3\%, también el número absoluto de contratación casi se duplicó entre 2010 y 2019.

Tabla 2. Trabajadores mexicanos del PTAT, por provincias

\begin{tabular}{|c|c|c|c|c|}
\hline Provincia & \multicolumn{2}{|c|}{$\mathbf{2 0 1 0}$} & \multicolumn{2}{|c|}{$\mathbf{2 0 1 9}$} \\
\hline Ontario & 8084 & 51.1 & 11331 & 42.9 \\
\hline Quebec & 3085 & 19.5 & 6333 & 24.0 \\
\hline Columbia Británica & 3061 & 19.4 & 6049 & 22.9 \\
\hline Alberta & 815 & 5.2 & 1177 & 4.5 \\
\hline Nueva Escocia & 175 & 1.1 & 568 & 2.2 \\
\hline Manitoba & 336 & 2.1 & 464 & 1.8 \\
\hline Isla P. Eduardo & 150 & 0.9 & 325 & 1.2 \\
\hline Saskatchewan & 97 & 0.6 & 120 & 0.5 \\
\hline Nueva Brunswick & 6 & 0.0 & 40 & 0.2 \\
\hline Terranova y Labrador & 0 & 0.0 & 0 & 0.0 \\
\hline Total & 15809 & 100.0 & 26407 & 100.0 \\
\hline
\end{tabular}

Fuente: Secretaría del Trabajo y Previsión Social (STPS).

\section{El Programa de Trabajadores Agrícolas Temporales (PTAT) y el trabajo no libre}

El PTAT se presenta como un programa modelo con beneficios para los dos países (Henestroza, 2003; Vanegas, 2000a, 2000b; Verduzco, 2000, 2015). Por ejemplo, Canadá puede regular la migración laboral temporal y cubrir con mano de obra extranjera su mercado laboral agroindustrial. Con respecto a México, se supone que los trabajadores tendrían garantizado un número de horas laborables, son trasladados de manera segura desde México hasta el lugar de trabajo, tienen hospedaje y no experimentarían la incertidumbre del trabajo indocumentado (como sí sucede en Estados Unidos).

Existe el supuesto de que cuando las personas se contratan o continúan en el PTAT lo hacen eligiendo libremente. Pero se omite que la elección está delimitada por estructuras sociales, económicas, jurídicas y culturales. Elegir libremente implicaría que el trabajador tiene opciones similares o mejores en México. Sin embargo, debido a las desigualdades estructurales de la economía capitalista, las oportunidades reales de trabajo en el mercado laboral agrícola mexicano están lejos de parecerse a las ofrecidas en Canadá o Estados Unidos (Barrón, 1998, 2005).

Ante las condiciones del mercado laboral en México, la posibilidad de que estos trabajadores puedan cubrir las necesidades básicas de sus familias como la alimentación, 
vestimenta, salud y educación y, excepcionalmente, ahorrar o mejorar sus condiciones materiales de existencia, radica en migrar a uno de esos dos países norteños, pero una vez que las familias entran en la lógica de las remesas, se vuelven dependientes de las mismas (Basok, 2000; Márquez, 2012; Preibisch, 2004a).

Luego, al estar en Canadá, la imposibilidad real de interponer una apelación ante un rompimiento unilateral de contrato por los empleadores, el temor a la deportación y a ser expulsado del Programa, agravan la imposición estructural. Así pues, la decisión de continuar o dejar el PTAT está coaccionada, lo cual contribuye a un sistema de trabajo no libre (Silverman \& Hari, 2016). Esta condición también existe para los trabajadores de otras nacionalidades que están insertos en otros programas de trabajo temporal de baja calificación en Canadá, incluso puede ser más intensa (Castracani, 2018, Muir, 2015; Preibisch, 2015; Vargas-Foronda, 2010).

En contraposición, los ciudadanos canadienses no experimentan en su territorio las situaciones anteriores, pues ellos sí tienen opciones de trabajo, no dependen de un solo ingreso (remesa), no experimentan temor a la deportación y a los abusos del empleador, capataz o mayordomo y, en caso de suceder, tienen acceso a un sistema institucional que los defiende. Es decir, ellos pueden ejercer una ciudadanía plena con acceso al trabajo libre y a la defensa de sus derechos.

El trabajo no libre, así como las formas de esclavitud, han existido en los distintos modos de producción. Pensadores como Adam Smith, John Stuart Mill, John Bright, entre otros, sostenían que dichas formas eran incompatibles con el capitalismo pues no eran eficientes, no permitían la especialización de tareas y eran costosas (Brass, 2011). Siendo así, las sociedades modernas y capitalistas deberían suprimirlas para dar paso al trabajo libre (De Vito \& Lichtenstein, 2016; De Vito \& Sundevall, 2017). Por esta razón es que aparecen instrumentos internacionales que declaran formalmente eliminar esas prácticas laborales incompatibles con los derechos humanos.

A pesar de las expectativas, las relaciones de trabajo no libre continuaban siendo frecuentes en países "tercermundistas". Se pensaba que se trataba de "una anomalía en el modo de producción capitalista" (Basok, 2002, p. 14) o más bien de aspectos residuales de épocas anteriores o que se debían a un desarrollo insuficiente del capitalismo (Lebaron, 2015; Sharma, 1995). Tales razonamientos ocultaban que aquellas formas eran (y son) compatibles e inherentes con la expansión del capitalismo, tanto en los países desarrollados, como en todo el mundo (Brass, 2011; De Vito \& Sundevall, 2017; Strauss, 2014).

Entonces, en las sociedades modernas y capitalistas surge una dicotomía en torno al trabajo, en un extremo están la esclavitud y el trabajo no libre, ambas, operando como mecanismos de control y, en el otro lado, el trabajo no esclavo que aparece como libertad y, desde luego, como algo deseable (Engerman, 2000).

$\mathrm{Al}$ transitar de la sociedad feudal al sistema capitalista, los siervos quedaron en libertad de venderse como mano de obra. Sin embargo, a pesar de que el trabajador es el libre poseedor de su fuerza de trabajo, también se ve obligado a venderla (Marx, 1973). Los trabajadores se encuentran en una situación contradictoria derivada de la propia estructura del capitalismo, son libres de vender su fuerza de trabajo, pero están obligados a venderla para sobrevivir ya que no poseen los medios de producción (Strauss, 2012, 2014).

En este artículo se entenderá por trabajo libre "la capacidad de vender la mano de obra, celebrar un contrato y recibir un salario acordado" (Strauss, 2012, p. 139). Mientras que el trabajo no libre es aquel que se genera cuando los individuos no 
pueden abandonar una relación laboral para buscar otro empleo, es decir, cuando no tienen movilidad entre mercados laborales (Satzewich, 1991) o para dejar temporal o definitivamente el mercado laboral. En el trabajo no libre se practican distintos grados y tipos de coerción, como por ejemplo amenazas, cautiverio, violencia o hasta la muerte (McGrath, 2005).

El trabajo no libre tiene variantes entre las que se pueden mencionar la esclavitud, el trabajo convicto, el trabajo de contrato forzoso, la servidumbre por deudas, el trabajo doméstico no remunerado, trabajo infantil, trata de personas, etcétera. Con respecto al trabajo forzoso, normalmente inicia mediante coerción, sin embargo, también ocurre que algunas relaciones laborales entabladas libremente, con reconocimiento legal, se vuelvan coercitivas debido a la estructura y operación contractual, reduciendo así la capacidad del trabajador para dar por terminado el contrato y buscar otro empleo (Strauss, 2012), algo similar tiende a ocurrir en el PTAT. En cualquier caso, la mano de obra no libre debe trabajar duro, no tanto por los "incentivos" económicos de la actividad realizada, sino, más bien, para evitar ser castigados (Brass, 2011).

Las prácticas laborales anteriores han sido evidenciadas por algunos académicos, por activistas sociales, por sindicatos y organizaciones no gubernamentales (Straus, 2014); además, se han prohibido por distintos mecanismos del derecho internacional en los Estados democráticos modernos (Basok, 2002; De Vito \& Sundevall, 2017). Por ejemplo, puede citarse la Convención sobre la Esclavitud (Oficina del Alto Comisionado de las Naciones Unidas para los Derechos Humanos [OACDH], 1926), también la Convención suplementaria sobre la abolición de la esclavitud, la trata de esclavos y las instituciones y prácticas análogas a la esclavitud (ONU, 1956) o el Convenio sobre la abolición del trabajo forzoso de la Organización Internacional del Trabajo (oIT, 1957).

En lo referente al PTAT, Tanya Basok se pregunta cuál es la ventaja de la fuerza laboral suministrada por el Programa para los granjeros canadienses, ya que resulta costosa debido a los gastos de transportación y al hospedaje. La respuesta radica en que funciona como trabajo no libre, específicamente como mano de obra cautiva, es decir, el trabajador no puede abandonar su empleo en búsqueda de otro, y porque está disponible para cualquier momento de la producción (Basok, 2002; Perry, 2018, 2019). Pero también es cautiva porque "El empleador dicta y regula en dónde y cómo viven los trabajadores" (Encalada, 2005, p. 17); normalmente la vivienda temporal de los migrantes se encuentra en las cercanías o dentro de la misma granja. También porque el trabajador no puede elegir al empleador o cambiarlo en caso de que no le parezca conveniente. $^{2}$ Estas características operativas del Programa tienen consecuencias socioespaciales en la integración y exclusión del migrante en la sociedad canadiense. Así que el PTAT, a la vez que se sustenta en acuerdos legales para dar ciertas "garantías" a los trabajadores, también representa un escenario donde se "difuminan las líneas entre la autonomía y la esclavitud, y el trabajo libre y no libre" (Silverman \& Hari, 2016, p. 96).

La operación del Programa tiene similitudes a una vieja relación de producción agrícola mexicana sostenida por mano de obra no libre: la hacienda mexicana. Tanto el PTAT como la hacienda se basan en la propiedad privada, producen para el mercado, emplean el trabajo ajeno y ciertas prácticas laborales no libres. La diferencia radica en que la hacienda recurría al sistema de servidumbre llamado peonaje, en donde el

${ }^{2}$ Solamente podría ser trasferido a otro patrón si el trabajo se ha terminado antes del tiempo estipulado en el contrato o si el patrón no asigna las horas pactadas. 
peón permanecía a disposición del hacendado mediante el endeudamiento a través de la tienda de raya (Montoya, 2005).

Por su parte, el PTAT es un instrumento dirigido por el Estado, en donde los migrantes tienen sueldos menores a los percibidos por los trabajadores locales (pero más altos que los obtenidos en México) y, debido a su estatus legal de trabajador temporal, admiten condiciones de explotación (Strauss \& McGrath, 2017), que los deja expuestos a la amenaza de que el empleador termine unilateralmente el contrato y luego sean deportados y expulsados del Programa.

Aunque formalmente las relaciones laborales que se derivan del PTAT no indican trabajo forzado o esclavitud (Strauss \& McGrath, 2017), sí se puede sostener que es un instrumento que combina el trabajo libre (vender la fuerza de trabajo, establecer un contrato y percibir un salario) con prácticas de trabajo no libre (cautiverio, estatus legal no pleno, condiciones laborales precarias, coerción, nula circulación laboral y reducida movilidad socioespacial).

Aunque la literatura académica sobre el PTAT ha destacado el efecto de las estructuras que coaccionan a los trabajadores, también se deben explorar más extensamente las estrategias de negociación, lucha o resistencia de los trabajadores agrícolas. Algunas investigaciones (Basok, 2000; Cohen, 2019; Cohen \& Caxaj, 2018; Silverman \& Hari, 2016) han reconocido que, si bien los trabajadores no tienen la opción de sindicalizarse o hacer huelga, sí recurren a formas cotidianas de resistencia; no están completamente controlados ya que pueden tomar decisiones, pero tales estrategias son difíciles de sostener, pues algunos migrantes prefieren no involucrarse en acciones de resistencia por temor a ser suspendidos.

El hecho de que los trabajadores no se manifiesten de manera pública y abierta contra los abusos de los empleadores, contra las restricciones del PTAT, la racialización laboral o la discriminación en la sociedad canadiense, no significa que carezcan de una conciencia de la acción política, por ello es importante identificar cómo los trabajadores usan las distintas formas de capital para producir otras formas de resistencia.

Es oportuno hacer referencia al trabajo de James Scott (2011) acerca de las formas de resistencia de los grupos dominados, pues en su obra se pone de manifiesto que los grupos dominantes nunca pueden ejercer el control total sobre los subordinados. La investigación del antropólogo muestra que cada imposición de estructuras de dominación genera posibilidades de reacción y estrategias de resistencia por individuos y grupos. Sin embargo, dichas respuestas no tienen que ser necesariamente abiertas, directas, públicas o explosivas: "muy probablemente crearán y defenderán, a escondidas, un espacio social en el cual se podrá expresar una disidencia marginal" (Scott, 2011, p. 19). A estas prácticas más bien discretas e indirectas, Scott las denomina infrapolítica; y son a las que recurren los trabajadores agrícolas mexicanos del PTAT.

Una forma de resistencia apoyada por redes de capital social en combinación con el capital cultural para lograr una integración comunitaria es el trabajo realizado por Adam Perry $(2018,2019)$, en Leamington, Ontario, quien mediante talleres enseña a los trabajadores agrícolas el uso de técnicas teatrales (Theatre of the Oppressed) para que representen su experiencia laboral en contextos de trabajo no libre y de exclusión social. Es decir, utiliza el arte para crear espacios de resistencia.

Otro ejemplo de resistencia apoyado en el capital social es la acción comunitaria de la antropóloga Amy Cohen y de Susana Caxaj (Cohen, 2019; Cohen \& Caxaj, 2018), quienes desde 2013, a través del colectivo "Radical Action with Migrants 
in Agriculture" (RAMA), han realizado trabajo de apoyo y asistencia a favor de los migrantes agrícolas temporales.

Estos dos ejemplos ilustran que al final, lo que se busca es contribuir a generar e incrementar el capital espacial de los trabajadores agrícolas (aunque los investigadores no lo conceptualicen de este modo) para que los migrantes puedan conquistar distintos espacios e insertarse en la sociedad canadiense.

\section{Ciudadanía y trabajo no libre}

La ciudadanía y la condición legal de trabajo temporal (no ciudadanía) de los migrantes agrícolas en Canadá es un aspecto estructural que legitima relaciones de dominación y subordinación. El hecho de que ellos no puedan ejercer la ciudadanía plena los vuelve un grupo laboralmente explotable y socialmente excluido (Baines \& Sharma, 2002; Sharma, 2000), lo que resulta en trabajo no libre.

Para reflexionar sobre la ciudadanía, se retoma la propuesta de Thomas Humphrey Marshall. Aunque su trabajo ha recibido varias críticas, entre las que destacan: tener una concepción progresiva de la aparición de los derechos, la ausencia de la perspectiva de género o consideraciones al origen étnico o la nacionalidad (Silva, 2014; Baines \& Sharma, 2002), también es cierto que funciona como un modelo analítico, un punto de partida que describe ciertos aspectos sociohistóricos.

Marshall toma el periodo entre los siglos xviII y xx. Su modelo tiene tres componentes: los derechos civiles, los políticos y los sociales. Los primeros son representativos del siglo xviII y defienden la libertad individual, por ejemplo, la libertad de pensamiento y expresión, la celebración de contratos, trabajar en donde se considere adecuado y hacer valer los derechos en los tribunales; "[los derechos civiles] confieren capacidad legal para luchar por lo que uno desea poseer" (Marshall, 1997, p. 315). A pesar de su existencia formal, el acceso a los mismos también era desigual, así que muchas personas quedaban fuera del cobijo de la ley.

El segundo componente es el de los derechos políticos, que se extendieron durante el siglo xix, los cuales brindan el derecho a votar y ser votado, es decir, participar en el poder político de un Estado-nación. Sin embargo, al continuar el avance del capitalismo y sus desigualdades inherentes, la aplicación de los elementos de este segundo componente quedó obstaculizada, pues "los derechos políticos de la ciudadanía, a diferencia de los derechos civiles, constituían una amenaza en potencia para el sistema capitalista" (Marshall, 1997, p. 320). Lo anterior explica el retardo en el reconocimiento del ejercicio pleno de las mujeres o de minorías étnicas a la ciudadanía plena.

El último componente es el de los derechos sociales, característicos del siglo xx, estos permitirían el bienestar económico y social y orientarían hacia la igualdad ante la ley, al disminuir los efectos de la desigualdad en el capitalismo; se trata de los derechos que permiten "vivir la vida de un ser civilizado conforme a los estándares corrientes en la sociedad" (Marshall, 1997, p. 303).

Los derechos sociales son parte de los derechos humanos, entre los cuales el trabajo está incluido y se reconoce en la Declaración Universal de los Derechos Humanos "toda persona tiene derecho al trabajo, a la libre elección de su trabajo" (onU, 1948). Igualmente está el Pacto Internacional de Derechos Económicos, Sociales y Culturales, 
que defiende el trabajo libremente escogido, en condiciones justas y favorables y el derecho a sindicalizarse y a la huelga (onU, 1966). De acuerdo con el Consejo Económico y Social (OACDH, 2005), cumplir con ese derecho es esencial para lograr la dignidad humana.

Entonces, la ciudadanía requiere de los tres componentes para que un individuo goce de todos los derechos y deberes y sea parte de una comunidad; representa un impulso hacia la igualdad y se contrapone a las desigualdades de clase del capitalismo (Marshall, 1997). Así pues, hay un conflicto permanente entre ciudadanía y capitalismo.

Ahora, si en el estudio de los mercados laborales se introducen las nociones de ciudadanía y estatus legal no pleno, aparecerá una forma de estratificación laboral. El estrato más alto estará ocupado por los ciudadanos, quienes teóricamente gozarían del ejercicio pleno de los tres componentes de la ciudadanía. Le seguirían los residentes permanentes. Después estarían otras categorías de trabajadores migrantes de alta calificación, luego los migrantes de baja calificación. Finalmente, en el estrato más bajo, estarían los trabajadores indocumentados, que en el marco de la ciudadanía "no tienen el derecho básico a tener derechos" (Goldring \& Landolt, 2015, p. 66). Si bien, en este sistema de estratificación puede existir movilidad ascendente, un cambio en la condición legal en Canadá no garantiza necesariamente la reducción de la precariedad, como se ejemplifica en el PTAT.

Los trabajadores mexicanos tienen un estatus migratorio legal que los precariza, pues los deja sin poder ejercer los derechos ciudadanos. La condición de esta mano de obra contribuye a limitar su inclusión social y espacial en Canadá, de tal manera que: "estos no-ciudadanos son parte de la sociedad canadiense y es poco probable que los vecinos o amigos los identifiquen como no libres o personas menos merecedoras de derechos" (Baines \& Sharma, 2002, p. 77). A estas restricciones se pueden agregar el desconocimiento del idioma, la discriminación por nacionalidad y por género, así como los procesos de racialización (Baines \& Sharma 2002; Preibisch \& Binford, 2008; Sharma, 2000, 2001; Silverman \& Hari, 2016). Sin embargo, el PTAT no es un aparato althusseriano que anule a los trabajadores, existen ciertos tipos de capitales, entre ellos el espacial, que les confiere un poder para resistir las restricciones mencionadas.

\section{Aspectos que estructuran el trabajo agrícola}

En general, el trabajo agrícola requiere de una mano de obra con gran resistencia para el desgaste físico y mecánico del cuerpo, y estar disponible para atender las distintas fases de los cultivos. La producción agrícola estacional o temporal está definida fuertemente "por el ciclo estacional de las plantas; por el tiempo que dure este, desde un par de semanas hasta casi todo el año" (Montoya, 2005, p. 23).

En Canadá, este sector productivo es uno de los que registran más rotación de mano de obra local debido a los riesgos, a las actividades extenuantes, al uso de maquinarias y a la exposición a pesticidas y a otros químicos (Gibb, 2006). La agricultura canadiense históricamente ha dependido de fuentes que suministran trabajo no libre, por ejemplo, se recurrió a huérfanos, jóvenes de internados, prisioneros de guerra y habitantes de los pueblos originarios (Preibisch, 2007). Esta práctica laboral continúa vigente a través de la mano de obra cautiva del PTAT. 
Para atender la menor cantidad efectiva de fuerza de trabajo local y sostener la competitividad de la agroindustria a nivel global, el Estado canadiense ha diseñado programas de trabajo temporal que formalmente dicen respetar los derechos de los trabajadores extranjeros de baja calificación, pero que, en la práctica, por su propio diseño legal y operativo, precarizan y obstaculizan el ejercicio de sus derechos.

\section{Campo del trabajo temporal agrícola migrante}

Con frecuencia, la explicación de los fenómenos sociales como la migración en los programas de trabajo temporal se plantea desde algún polo de la relación sociedadindividuo. Por un lado, hay enfoques que destacan la aplastante tiranía de las estructuras de la vida social y, por el otro, perspectivas que defienden la espontaneidad de la acción individual. El resultado es la existencia de dos enfoques falsamente opuestos, uno objetivista, centrado en la estructura, el otro es el subjetivista, centrado en la acción individual (Bourdieu \& Wacquant, 1995).

El concepto de estructura se refiere a los distintos niveles de la vida social que constriñen y limitan las acciones de los actores (Giddens, 2006), por ejemplo, los sistemas de estratificación social, el modo de producción capitalista, el mercado agrícola internacional, los programas de trabajo temporal, por citar algunos. Todos, en términos funcionalistas, se interrelacionan para dar estabilidad y continuidad a la vida social. Por su parte, la categoría de acción individual es utilizada para destacar el voluntarismo y el actuar racional de los individuos; supone que ellos actuarían en la sociedad por intereses y motivaciones particulares, al controlar sus propias condiciones de vida (Ritzer, 2002).

Esta falsa dicotomía sociedad-individuo limita la comprensión de los fenómenos sociales y espaciales. Sin embargo, existen algunas perspectivas teóricas que pueden salvar esta oposición, una de estas es la sociología reflexiva de Pierre Bourdieu, la cual se emplea aquí para comprender el margen de acción que tienen los trabajadores agrícolas en contextos estructurales de trabajo no libre. Para tal efecto, se recurre a cinco conceptos básicos interconectados, a saber: el espacio social, el campo, agencia, el capital y el habitus.

Para Bourdieu, el espacio social es una construcción histórica de relaciones, "es un espacio pluridimensional de posiciones" (Bourdieu, 2011, p. 20) que surge por una distribución desigual de ciertos activos llamados capitales y que son objeto de lucha por los diferentes agentes sociales (individuos, colectivos, grupos, instituciones), lo que da paso a "una estructura de posiciones diferenciadas, definidas, en cada caso, por el lugar que ocupan en la distribución de una especie particular de capital" (Bourdieu, 1997, p. 28). Entonces, el contar o no con algunos tipos de capital, montos de estos, así como el capital global, es lo que organiza las posiciones sociales superiores o inferiores, dominantes o subordinadas (Giménez, 2005).

El espacio social es también un campo, ya que es el lugar donde se expresan las luchas por controlar las formas de capital y así reorganizar la estructura de las posiciones de los agentes (Bourdieu, 1997). Podría decirse que el espacio social está conformado por múltiples campos que son parcelas del espacio social global.

Un campo es el espacio socialmente estructurado de las relaciones históricas entre sus ocupantes. Es la arena de conflicto específica en la cual los agentes se relacionan, 
agrupados y contrapuestos por sus posiciones y disposiciones (habitus). Los agentes buscan, por un lado, controlar o monopolizar los activos o capitales y, por el otro, excluir a los competidores (Bourdieu, 2002).

Más allá de la definición que pueda hacerse del campo, su importancia reside en que se trata de una herramienta que define propiedades generales del espacio social global y de todos los campos. Por ejemplo, muestra que todos estos espacios son sistemas de fuerzas, de competencia o de luchas en el que los participantes o agentes se oponen y se agregan, estructurando relaciones de dominación o subordinación. Por otro lado, también permite descubrir las "propiedades específicas propias de un campo particular" (Bourdieu, 2002, p. 119), es decir, conocer a los distintos participantes (individuos, grupos, instituciones), las particularidades de la competencia, del conflicto y de las luchas por el control de los activos.

Una ventaja de utilizar la teoría de los campos es que permite establecer las estructuras que se imponen a los individuos, pero también reconocer que, a la manera de un juego, los participantes consideran que jugarlo vale la pena, que pueden obtener ganancias, por ello Bourdieu señala la necesidad de incorporar en el estudio del campo "una teoría de los agentes sociales" (Bourdieu \& Wacquant, 1995, p. 25).

Cuando los actores en el campo son los individuos, estos no aparecen como enteramente racionales, voluntariosos o libres de cualquier condicionamiento. Por el contrario, son agentes, lo cual significa que están constituidos socialmente a través de un conjunto de disposiciones y esquemas (habitus) que les permite actuar en el campo y producir efectos en este (Bourdieu \& Wacquant, 1995).

Aquí se entiende por agencia el poder o la capacidad de acción de los participantes para producir efectos en un campo y para luchar y competir por formas de capital. Hay que insistir, la agencia no es el libre actuar de los individuos, sino que es facilitada por la estructura del campo, por la posesión de especies de capital y por el habitus.

Los agentes ocupan distintas posiciones (dominantes, subordinados o cualquier otra) a las cuales se asocian ciertas disposiciones y esquemas que encierran prácticas culturales, maneras de consumir, opiniones políticas, formas de actuar en el mundo, etcétera, es lo que Bourdieu denomina habitus. El concepto de habitus permite entender que el actuar de los individuos no surge espontáneamente, sino que sus "acciones están enmarcadas dentro de categorías de percepción y apreciación histórica y socialmente constituidas" (Bourdieu \& Wacquant, 1995, p. 71). Los agentes deciden, pero en el marco de las posibilidades interiorizadas. El habitus representa el conjunto de reglas que no han sido creadas intencionalmente, pero que están depositadas en las mentes y en los cuerpos de los agentes, por eso constituyen las disposiciones y esquemas que les informan cómo jugar en los distintos campos.

De este modo, existen múltiples campos como el del poder, el intelectual, el de la política, de la moda, del deporte, del arte, el universitario, etcétera, pero todos construidos analíticamente por la o el investigador. Del mismo modo, la migración laboral puede concebirse como un campo que, a su vez, se parcela en subcampos.

Para fines de este artículo, propongo construir el circuito laboral agrícola del PTAT como el campo del trabajo temporal agrícola migrante en Canadá. Lo cual se justifica porque, en primer lugar, el PTAT ha derivado de relaciones históricas de la producción agrícola canadiense basada en mano de obra no libre. Segundo, la mayor parte de los trabajadores mexicanos del Programa han mantenido una relación con las faenas del campo. Tercero, los campesinos han enfrentado históricamente desventajas estructurales como fluctuaciones en el precio de sus productos, bajos salarios, falta 
de tecnología para explotar la tierra o contracción de los mercados laborales. Cuarto, se trata de un espacio relacional principalmente de dos tipos de agentes agrupados y contrapuestos, es decir, los granjeros canadienses y los trabajadores agrícolas que, por estrategia de reproducción social, abandonan temporalmente su residencia en México para ir a laborar a Canadá.

Los empleadores ocupan la posición dominante debido a que poseen varias especies de capital y montos suficientes para imponerse, pero no significa que controlen definitiva y absolutamente el campo. Los segundos son los trabajadores, quienes están en una relación de subordinación. Sin embargo, ellos no quedan anulados por las estructuras de poder y dominación del campo; son agentes que disputan los activos y tienen la capacidad de usarlos para ejercer una influencia o un efecto a su favor en contextos de trabajo no libre y decidir resistir, negociar o aceptar las relaciones de poder. Por ejemplo, ante las formas de control, Jorge, ${ }^{3}$ de un invernadero de flores, en Saint-Eustasche, intenta motivar a compañeros de otras granjas a no aceptar abusos.

Acá estamos vendidos amigo. Aquí llueva, truene o relampaguee no puedes decir no [...] Realmente a las personas de aquí, ellos nos toman como animales, como animales de trabajo [...] Aquí pegadito hay una granja, fui a saludar a los muchachos y andaba su patrón, pero ni uno de ellos habló. “¿Quién es el jefe?” [preguntó Jorge] y uno me hace así [una seña para indicar al jefe] "bonjour monsieur", ni me peló siquiera. "No compas, mándenlo a la jodida, hay unas 5000 granjas para venir aquí [...] Esta gente no merece nada" (Jorge, 2011, entrevista individual. Saint-Eustasche, Quebec).

Un capital es un activo, un poder que permite a su poseedor ejercer una influencia a su favor dentro de un campo. Bourdieu normalmente se refiere a cuatro tipos principales de capital, el cultural, el económico, el simbólico y el social (Bourdieu, 1997, 2008, 2011). Sin embargo, deja abierta la posibilidad de identificar otros, según sean útiles o válidos, es decir, que funcionen en el campo en cuestión, es lo que denomina capitales eficientes (Bourdieu, 1997; Bourdieu \& Wacquant, 1995). De este modo, para el campo del trabajo temporal agrícola migrante pueden ser eficientes, al menos, el capital lingüístico, el jurídico, el social y el espacial. El capital lingüístico es una forma del capital cultural y se observa mediante el conocimiento y uso del idioma francés e inglés por los migrantes agrícolas. El capital jurídico tiene que ver con el estatus legal (tanto el de los trabajadores temporales como el de los ciudadanos), con el conocimiento de los derechos y con las instancias en donde podrían hacerlos valer. El capital social se observaría en las redes que los jornaleros han tendido en Canadá, tales como los contactos con organizaciones sindicales, civiles, religiosas, amistades y las acciones de apoyo por la sociedad civil. En cuanto al capital espacial, este será abordado más adelante.

Los niveles o montos de capital pueden ser nulos o muy bajos para los trabajadores que se incorporan por primera vez al Programa, pero se van incrementando en cada temporada, incluso, a pesar de ser cambiados de granjas, de localidad o de provincia.

Un capital puede intercambiarse por otro si la estrategia de los agentes así ha sido trazada. Por ejemplo, si un trabajador, antes de entrar en el Programa sabe operar tractores o montacargas, esto le brindaría una probabilidad para ocupar el puesto

\footnotetext{
${ }^{3}$ Con el propósito de mantener el anonimato, los nombres de los trabajadores han sido cambiados.
} 
correspondiente en alguna granja, lo cual podría mejorar su salario. De este modo, el capital cultural se intercambió por capital económico.

Por otro lado, el poder y la dominación son conceptos clave en el campo, así que necesitamos explorarlos un poco más para posteriormente ligarlos con el capital. Michel Foucault escribió que el poder está presente en toda la vida social, se inviste en las instituciones y en los sujetos: "transita transversalmente, no está quieto en los individuos" (Foucault, 1979, p. 144). Se trata de un conjunto de prácticas históricas que construyen a los individuos y a las instituciones. Foucault suele nombrarlas tecnologías o dispositivos. Así, el pтAT es un dispositivo de poder resultado de las relaciones históricas del capitalismo en la agricultura canadiense.

Para Max Weber, el poder es la probabilidad de imponer la propia voluntad en una relación social a pesar de encontrar resistencia (Weber, 1964). En cuanto al concepto de dominación, el sociólogo alemán propone entenderlo como "la probabilidad de encontrar obediencia para un mandato por parte de un conjunto de personas" (Weber, 1964, p. 43). Lo interesante de la definición weberiana es que el poder y la dominación son probabilidades, hay un rango en el cual la imposición de la propia voluntad o la de encontrar obediencia a un mandato podría no ocurrir. Entonces, articulando las definiciones de Foucault y Weber, las tecnologías o dispositivos de poder tienen una probabilidad, tanto de ser impuestas sobre otros y de encontrar obediencia a sus mandatos, como de no imponerse o de no ser obedecidas, lo anterior debido a la capacidad de agencia de los participantes del campo.

En el campo del trabajo agrícola temporal, los dueños de las granjas, que son agentes dominantes, ejercen poder y dominación, pero al tratarse de una probabilidad, entonces pueden encontrar resistencia o no obediencia por los trabajadores agrícolas, esto dependerá del tipo y cantidad de capital eficiente disponible para ejercer un poder, de la posición históricamente determinada en el campo y de las estrategias emprendidas.

\section{Espacialización y el capital espacial}

El espacio físico y el social frecuentemente se abordan como dimensiones antagónicas. El primero como un recipiente que es llenado por las relaciones sociales; el segundo, como una abstracción, sin sustrato material, que adopta la forma del contenedor. Aquí propongo que, al igual que en la relación antagónica estructura-agencia, también se trata de otra falsa dicotomía, lo social y físico mantienen una relación simultánea y su distinción es analítica.

En este trabajo la espacialización se refiere a las prácticas y relaciones sociales que se observan o están inscritas en el espacio geográfico. Las relaciones sociales que estructuran el campo del trabajo temporal agrícola migrante tienen consecuencias observables en el espacio, es decir, espacializadas. Dicho esto, los trabajadores agrícolas disputan el control de los capitales eficientes del campo para conservar o mejorar sus posiciones en el espacio social y geográfico o, mejor dicho, sus posiciones socioespaciales.

Un ejemplo de esto se aprecia en la localización de las residencias de los trabajadores y de los finqueros en Canadá, la cual no es casual, su distribución expresa una traducción de las jerarquizaciones sociales y económicas, es decir, una espacialización de las relaciones de dominación y subordinación. Aunque granjeros y migrantes suelen habitar en el mismo espacio rural, sus condiciones materiales son 
opuestas. Los trabajadores habitan en el sitio designado por el patrón, regularmente en lugares adaptados en bodegas, o bien casas móviles prefabricadas que favorecen la falta de privacidad y el hacinamiento y frecuentemente están ocultas detrás de la granja o de la casa de los finqueros, situación que propicia la vigilancia y control de las salidas de los trabajadores y de las visitas que reciben, así como la invisibilidad ante los vecinos. Asociado a ello, los migrantes enfrentan restricciones de movilidad espacial pues el acceso a los medios de transporte motorizado está limitado.

En cuanto a los empleadores, ellos no viven en espacios modificados, sino en casas formalmente reconocidas como tales, con registro catastral y títulos de propiedad que los hace dueños de estas. Son residencias amplias y decorosas, con espacios privados para la familia, no hay hacinamiento y cuentan con todos los bienes y servicios. Además, tienen vehículos para trasladarse sin restricción. La residencia se encuentra al pie de camino, así que tienen libre acceso a las vías de comunicación.

El espacio tendría una doble característica, por un lado, es arena de lucha y conflicto entre agentes dominantes y dominados, esto es así porque las formas de jerarquización y conflicto social se espacializan. Por el otro, el espacio se vuelve una influencia, un activo (Lévy \& Lussault, 2003), es decir, una forma de capital por controlar: "es un arma $[\ldots]$ para imponer el punto de vista dominante de la organización espacial de la población" (Fogle, 2009, p. 207).

Por esta segunda característica es que se propone pensar el espacio como un recurso, un poder, un tipo de capital, al cual llamaré simplemente el capital espacial, que constituye una forma eficiente dentro del campo del trabajo temporal agrícola migrante en Canadá. El capital espacial es un planteamiento relativamente reciente, por lo cual lo trataré más bien como una noción y no como un concepto acabado. El punto de partida ha sido el capital definido por Bourdieu y se ha reformulado desde la geografía (Lévy, 1994, 2002; Lévy \& Lussault, 2003; Rérat, 2018; Rérat \& Lees, 2011) y la sociología (Apaolaza \& Blanco, 2015; Centner, 2003, 2006, 2008; Kaufmann et al., 2004).

Cabe agregar que, mediante la intercambiabilidad, la acumulación de capital espacial por los trabajadores agrícolas podría favorecer el incremento del capital social, el lingüístico o el económico. También podría suceder a la inversa, es decir, los activos sociales o culturales podrían intercambiarse o sumar capital espacial. En el siguiente extracto de entrevista se observa la intercambiabilidad del capital social (las personas conocidas del trabajador) junto con el espacial (recorrido por distintos caminos y granjas), ambos incrementan el lingüístico, lo que permite al entrevistado obtener un mayor sueldo (capital económico). Se trata de David, empleado en una granja de verduras en el municipio de Laval.

[Entrevistador: ¿Tú cómo aprendiste francés?] Pues me interesé en aprender cuando trabajé en Saint-Rémi, iba una señora a vender cigarros [...]. Me gustaba platicar con ella y me decía "acompáñame a vender cigarros". Ella era quebequense, hablaba español e iba a las granjas. Yo le preguntaba dudas que tenía, los letreros que veía "¿Ahí qué dice?”, "Dice esto" [...]. Así, poco a poco. De ahí conocí a otra señora, se llamaba María, era de Sonora. Nos enseñaba un poquito, lo básico, el bonjour, el bonsoir, bonuit, saludos o pedir en un restaurant. Ya cuando llegué yo aquí, con este patrón, yo varias cosas ya sabía, los colores, las legumbres, los números y el patrón pensaba que yo hablaba muy bien, pero a veces salía con cosas que yo no sabía qué. Eso del idioma siento que me ha dado ventajas, Hay otros lugares en los que sí se 
requiere mucho del idioma, porque te mandan a una cosa, te mandan a otra, se requiere más, es muy necesario. Es importante, porque a mí me pagan un poquito más, siento que me pagan más por lo que sé, por lo que he aprendido (David, 2011, entrevista individual. Laval, Quebec).

Líneas más arriba se menciona que las disposiciones y esquemas del habitus orientan el actuar de los agentes. De este modo, lo que los empleadores y los trabajadores migrantes hacen con y en el espacio no surge espontáneamente, sino que se origina por la socialización y exposición a un orden socioespacial históricamente estructurante y estructurado. El habitus brinda información sobre cómo desempeñarse en el espacio, de lo que puede hacerse, de los modos de acceder, de movilizarse, de apropiárselo, de aprovechar sus elementos como un activo para conquistar mejores posiciones, es decir, usarlo como capital espacial.

A modo de ejemplo, se hace referencia a la entrevista colectiva 1 (2011) efectuada en un invernadero del municipio de Mirabel, en la parte noreste de la cmM. Cuando los trabajadores descansan o tienen tiempo libre, algunos salen a la población más cercana. A pesar de no tener acceso a un automóvil o a una bicicleta, ellos emprenden una caminata para ir a un bar, comer en algún restaurante, hacer alguna compra, quedar con algún amigo o pasear. Sin embargo, no caminan por la carretera pues es peligroso, en cambio, cortan camino a través de los cultivos, así hasta llegar a las afueras del pueblo. Además, la vivienda de los trabajadores está en el terreno de la finca y la casa del granjero a un costado, así que él vigila y controla las salidas y posibles visitas.

Para salir de la granja y lograr la apropiación y el uso del espacio, es decir, usar su capital espacial, los trabajadores enfrentaron varios obstáculos. El primero fue encontrar un punto lejos de la vigilancia del patrón, se trató de un pequeño canal de riego a un costado del terreno. El siguiente consistió en lograr cruzar el canal, lo consiguieron colocando una tarima a modo de puente. La última dificultad fue abrir brecha y no perderse entre los cultivos. También se debe anotar que los trabajadores saben que están pasando por propiedad privada y los dueños les han ordenado no andar por ahí, sin embargo, desafían las órdenes y continúan atravesando. Entonces, se trata de una estrategia de resistencia que implica el uso y apropiación del propio espacio y sus elementos para desafiar la vigilancia y el control ejercido por los empleadores. Estas acciones son comunicadas a los nuevos trabajadores de la granja o de otras cercanas para usar los mismos caminos. De este modo el espacio es el sitio de conflicto y arena de lucha y, al mismo tiempo, es un activo, un poder, una forma específica de capital para resistir las relaciones de dominación y conquistar posiciones en la sociedad canadiense.

Entonces, pese a las restricciones, los trabajadores logran desenvolverse afuera de la granja (Preibisch, 2004a, 2004b). Andar a pie por brechas o caminos, acceder a camionetas o automóviles de la granja y contar con bicicletas, todos estos son indicadores del capital espacial que posibilitan a los trabajadores contrarrestar aquellas restricciones espaciales y obtener una relativa libertad de desplazamiento que, a su vez, se traduce en una acumulación progresiva de capital espacial y mayor conocimiento del espacio. Para ilustrar lo anterior, está el caso de Zenen, participante de la entrevista colectiva 2 en una granja de verduras de Saint-Rémi, quien, además, gracias a su capital social, ha explorado lugares en otras provincias. 
Acá, $[\ldots]$ yo me voy al bar, pues más que nada, a distraerme del trabajo, me voy a jugar billar, a escuchar música y si se presenta la oportunidad de bailar, pues bailo con las personas, con las señoritas. Todas las veces que he ido nunca me han negado la pieza.

En Ontario fui, se me presentó una oportunidad de conocer las cataratas del Niágara y yo fui, yo no me lo perdí, yo nada más hablé con el capataz; ahí trabajábamos los domingos y le dije: "hay algún problema si voy a Niágara, quiero descansar el domingo". El capataz dijo que sí podía ir. Me invitaron unas señoras que trabajan ahí. “¿No quieres ir a las Niágaras?” Y les pregunté “¿Cuánto saldría el boleto?” "te sale en diez dólares que incluye el desayuno, la comida y el café", pues estaba bien. Nos llevó un guatemalteco, fuimos quince personas. En el transcurso del camino pasamos a un Tim Hurton [cafetería] y nos compró una caja de donas y el café. Llegando allí, desayunamos a las nueve o diez de la mañana, en los parquecitos hay asador, pusimos las carnes que él ya la llevaba preparada, nada más a calentar tortillas y asar (Zenen, 2011, entrevista colectiva 2. Saint-Rémi, Quebec).

Una vez por semana los trabajadores son llevados a un supermercado para comprar su despensa, el patrón renta un autobús, o bien cuando el número de trabajadores es reducido, entonces el traslado se realiza en alguna camioneta de la misma empresa que queda a cargo de algún trabajador de confianza, en este último caso, varios trabajadores logran un uso discrecional del vehículo, de tal modo que deciden moverse por distintos puntos de la población cercana $\mathrm{o}$, inclusive, ir a otras poblaciones o granjas. Por ejemplo, volviendo al caso de Jorge, él usaba una camioneta que los empleadores le prestaron, la cual utilizaba para ir y venir con sus compañeros desde la residencia hasta el invernadero (la residencia temporal de los trabajadores se encontraba alejada de la granja, en la zona urbana de Saint-Eustache), además, él usaba el vehículo para moverse (junto con sus compañeros de trabajo) libremente por la zona.

Como se vio más arriba, los desplazamientos a pie son un medio por el cual los trabajadores se apropian del espacio y aumentan su capital espacial. Ahora, con respecto a la bicicleta, esta se vuelve un medio de transporte clave para que ellos salgan de la granja a las poblaciones cercanas o a visitar otras granjas. La disponibilidad de bicicletas reduce la dependencia con respeto al patrón. Distintos actores de la sociedad civil han realizado donaciones de bicicletas a los trabajadores, lo cual ejemplifica que el capital social se convierte en capital espacial para usar el espacio, apropiárselo y conquistar inclusión social en Canadá. En el siguiente fragmento, nuevamente con Jorge, pero ahora laborando en otra granja, en la misma temporada, pues fue transferido, se aprecia una relativa libertad de salida de la finca en el momento que lo requería, después de la jornada laboral:

[Entrevistador: ¿Ahora cómo haces las compras?] Voy en mi bicicleta o me pego con uno de ellos [compañeros que sí tienen a su disposición una camioneta]. O yo agarro mi bicicleta, aquí está un marché, aquí está en SaintBenoît, aquí hay un marché, una tienda.

[Entrevistador: ¿Cuánto te haces a San Benito?] Como 10 minutos y 15 de regreso, está más pesadito por la subidita. Voy de volada, ida y vuelta. Pues me gusta pedalear (Jorge, 2011, entrevista individual. Saint-Eustasche, Quebec). 
El establecimiento y fortalecimiento de los vínculos de los trabajadores con ciudadanos, residentes permanentes e inclusive con compañeros de otras granjas (es decir, acumulamiento de capital social), también contribuye al desarrollo del capital espacial. Algunos trabajadores establecen amistad con otros empleados locales que laboran en la misma granja, esto ha permitido que algunos migrantes sean invitados por estas personas a visitar bares, restaurantes, acudir a espectáculos, eventos deportivos y lugares emblemáticos en otras ciudades. Un extracto de entrevista a Fernando, trabajador de una granja de verdura de Saint-Rémi, al sur de la cmM, sintetiza estas situaciones:

Tengo un amigo en Montreal [...] para mí es buena gente $[\ldots]$ antes yo me iba con él [...] y me sigue invitando a ver los espectáculos, aquí en el centro, aquí en el estadio olímpico [de Montreal]. Yo iba a quedarme allí en su departamento, allí donde él vivía (Fernando, 2011, entrevista individual. Saint-Rémi, Quebec).

En otro fragmento de entrevista, correspondiente a Rogelio, de una granja de cebollas, en Saint-Patrice-de-Sherrington, al sur de la cMM, se ejemplifica la necesidad de mantener vínculos con compañeros de granjas vecinas, pero aparece el temor de cometer alguna falta que perjudique a otros trabajadores o a él mismo:

[Entrevistador: ¿Tú has ido a visitar a trabajadores a otras granjas?] Sí, ahí están los vecinos. La verdad me da gusto, por ejemplo, ir a visitarlos. Nada más que siempre [...] el temor de que a lo mejor el patrón los vaya a regañar por mi culpa o tome represalias en contra mía y se lo diga a mi patrón. Siempre yo con la desconfianza, pues (Rogelio, 2011, entrevista individual. Saint-Patricede-Sherrington, Quebec).

Para los trabajadores que llevan varios años participando en el Programa o que tienen contratos largos, de entre seis y ocho meses, Incrementar el capital espacial les ayuda a sobrellevar su estancia en Canadá y el alejamiento de su hogar en México. Una vez más, el caso de David permite ilustrar su identificación y conocimiento con el espacio geográfico canadiense, después de varios años de trabajar allá. En el segundo fragmento, Patricio, empleado en un invernadero de flores, en Mirabel, expresa un conflicto en su identificación con Canadá y México.

[David] Después de 12 temporadas, ya lo veo muy normal [...] Incluso, le digo a mi esposa, yo creo que conozco más allá en Canadá para salir con la camioneta que en Toluca, casi no voy allá. En cambio, acá en Canadá me desplazo más que allá [en México]. A Toluca no entro porque siento que no conozco las entradas y las salidas, es más complicado, aquí es más fácil [en Canadá]; me siento muy seguro, seguro de mí mismo; me siento bien, con confianza de salir, de trasladarme de un lugar a otro, con confianza. Ya se me ha hecho muy familiar. No me siento raro de preguntarme en dónde estoy o si ya se hizo de noche. Disfruto mi estancia (David, 2011, entrevista individual. Laval, Quebec).

[Patricio] Vivo más tiempo acá (Canadá), alguien dijo "A lo mejor piensas como un quebequense, tú ves porque tienes más vida aquí que en México". No es porque yo esté a favor de aquí [...] Pero el que viene de tres o cuatro meses ¿qué vive aquí? vive más en Guatemala, Honduras o México, pero yo 
que estoy ocho meses y 20 días, viniendo durante siete años ¿dónde he vivido más mi vida? Pues aquí, más tiempo en Canadá que en México (Patricio, 2011, entrevista individual. Mirabel, Quebec).

A su vez, la información acumulada sobre el uso y apropiación del espacio se vuelve factor clave para ayudar a nuevos compañeros de la misma granja o de otras. De nuevo, David, quien, en el momento de la entrevista, tenía prestada una camioneta de la granja y estaba autorizado para usarla a discreción.

[A los compañeros] les he dicho donde depositar [envíos de dinero a México]. Por ejemplo, aquí donde estoy, siempre enviaban en Western Union, entonces les digo: "ahí no envíen, mejor los voy a llevar ahí con doña Betsy" [...] o los llevaba yo a Montreal, a Jean Talon, ahí está mejor. Después de allí, ya conocí por acá, [...] en Saint-Eustache, como no sabían llegar, pues los llevé. Ahora ya los llevo allá, ahora que estoy trabajando con ellos, cuando ellos cobran pues yo los llevo, está mejor, quedan contentos (David, 2011, entrevista individual. Laval, Quebec).

Las entrevistas anteriores destacan el valor del espacio como un recurso, una forma de capital que confiere a los trabajadores temporales agrícolas en Canadá una capacidad de agencia para enfrentarse a las disparidades de poder dentro del campo del trabajo temporal agrícola, en donde los empleadores tienen amplias cuotas de diversos capitales que los posicionan como dominantes. Otras formas de capital como el lingüístico y el capital social, representado por el apoyo de conocidos, amigos, organismos civiles, sindicatos o miembros de la comunidad son esenciales para generar y elevar ese activo.

\section{Conclusiones}

Surgen algunas preguntas ¿El Programa de Trabajadores Agrícolas continuará funcionando como trabajo no libre? ¿Los trabajadores agrícolas siempre se mantendrán en posiciones inferiores? ¿La capacidad de agencia es suficiente para que los migrantes puedan modificar las condiciones desventajosas del campo del trabajo temporal agrícola? ¿Qué más se requiere para modificar y disminuir las asimetrías de poder del campo en cuestión?

Responder a estas preguntas no es tarea fácil, sin embargo, en estas cuartillas se ha intentado exponer que las estructuras de dominación generan espacios en donde existe la probabilidad de que los trabajadores, en su posición subordinada, reaccionen ante esas imposiciones a través de la resistencia, la negociación o la aceptación. En cualquiera de estos casos, ellos requieren de ciertos activos, es decir, formas de capital eficientes para contar con un poder y ejercer así una influencia de acuerdo con sus intereses.

Con frecuencia, los trabajadores del Programa han recurrido a formas discretas e indirectas para resistirse a los contextos de trabajo no libre, lo que Scott (2011) denomina infrapolítica. Me parece que esta lucha política puede potenciarse y tener efectos más duraderos y profundos sobre el campo en la medida en que los trabajadores incrementen y combinen los distintos capitales como el lingüístico, social, jurídico, económico y el espacial. Las redes de apoyo, en tanto capital social, son fundamentales en esta lucha, pero el capital espacial aterriza en el espacio la lucha y la resistencia. 
El PTAT, desde el discurso institucional, promueve un conjunto de beneficios para ambos países y, en especial, para los trabajadores mexicanos. Sin embargo, al analizarlo, se puede identificar que las condiciones y reglas de operación los pone en desventaja, pues limita sus relaciones socioespaciales en Canadá.

En las sociedades modernas e industrializadas, los Estados protegen el ejercicio pleno de los derechos civiles, políticos y sociales, por ello, los ciudadanos canadienses pueden buscar y elegir libremente el trabajo que deseen y si se enfrentan a situaciones de abuso laboral cuentan con institucionales que los defienden. Esto no es el caso de los trabajadores agrícolas, pues su estatus de trabajador migrante temporal no les permite ejercer derechos ciudadanos, lo cual los precariza.

En el Programa, el contrato representa un acuerdo entre personas libres e iguales ante la ley, pero en la práctica se trata de una relación desigual, de tal modo que el PTAT es un dispositivo de poder, un instrumento que combina el trabajo libre (vender la fuerza de trabajo, establecer un contrato y percibir un salario) con prácticas de trabajo no libre (estatus legal y condiciones laborales precarias, coerción, nula movilidad laboral y reducida movilidad socioespacial).

Incorporar el espacio en el análisis permite pensar en dos características simultáneas, la primera es que constituye una arena de lucha, el sitio de conflicto de las relaciones de poder entre trabajadores y empleadores. La segunda es que, al mismo tiempo, constituye un capital, una herramienta para influir sobre la organización espacial y conquistar mejores posiciones para su beneficio en contextos de trabajo no libre.

Finalmente, un tema no abordado en el artículo que puede dar pie a futuros trabajos es el de género. Si bien, el PTAT es un espacio masculinizado, también son contratadas mujeres para trabajar en las granjas canadienses. Las jornaleras están en una doble situación de subordinación, pues, por un lado, deben enfrentar los aspectos estructurales del Programa y, por el otro, también deben hacer frente a relaciones socioespaciales conquistadas por ciertas formas hegemónicas de masculinidad. En este sentido, cabe la siguiente pregunta ¿cuál es la relevancia del capital espacial para que ellas conquisten y se incluyan en una sociedad en la que no cuentan con el ejercicio pleno de sus derechos ciudadanos y que, además, deben contender con prácticas de género de un mercado laboral preponderantemente masculino, es decir, asimétrico?

\section{Referencias}

Apaolaza, R. \& Blanco, J. (2015). Sobre capacidades, experiencias y posibilidades de uso y apropiación de la ciudad: breve estado del arte del concepto de capital espacial. XI Jornadas de Sociología. Facultad de Ciencias Sociales, Universidad de Buenos Aires, Buenos Aires. https://www.aacademica.org/000-061/969

Baines, D. \& Sharma, N. (2002). Migrant workers as non-citizens: the case against citizenship as a social policy concept. Studies in Political Economy, 69(1), 75-107. https://doi.org/10.1080/19187033.2002.11675181

Barrón, A. (1998). Migraciones internas e internacionales. Mercados primarios, condiciones de trabajo secundarias. Jornaleras a San Quintín, Baja California, México y a Niagara on the Lake, Ontario, Canadá. unAm.

Barrón, A. (2005). Los trabajadores mexicanos en los mercados de trabajo agrícolas de usa y Canadá. El caso de los jornaleros en Salinas, Greenfield y Watsonville, 
California, usA, y Simcoe, Ontario, Canadá. Revista Mexicana de Estudios Canadienses, (9), 49-72.

Basok, T. (2000). Migration of Mexican seasonal farm workers to Canada and development: obstacles to productive investment. International Migration Review, 34(1), 79-97. https://doi.org/10.1177\%2F019791830003400104

Basok, T. (2002). Tortillas and tomatoes. Transmigrant Mexican harverster in Canada. McGill-Queen`s University Press.

Basok, T., Bélanger, D. \& Rivas, E. (2012, abril). ¿Dejar el contrato? Competencia laboral, disciplina y agencia entre los trabajadores temporales mexicanos en Canadá. Segundo Seminario Permanente de Investigación sobre Migración México-Canadá. unAm, Université de Montréal.

Bourdieu, P. (1997). Razones prácticas sobre la teoría de la acción. Anagrama.

Bourdieu, P. (2002). Campo de poder, campo intelectual. Itinerario de un concepto. Montressor. Bourdieu, P. (2008). Homo academicus. Siglo Veintiuno Editores.

Bourdieu, P. (2011). Las estrategias de la reproducción social. Siglo Veintiuno Editores.

Bourdieu, P. \& Wacquant, L. (1995). Respuestas por una Antropología Reflexiva. Grijalbo.

Brass, T. (2011). Primitive accumulation, capitalist development and socialist transition: still waiting for Godot? Journal of Contemporary Asia, 41(1), 1-24. https:// doi.org/10.1080/00472336.2011.530034

Castracani, L. (2018). Importar el trabajo sin las personas: la racialización de la mano de obra agrícola temporal en Canadá. Revista THEOMAI, (38), 55-68. http://revista-theomai.unq.edu.ar/NUMERO_38/4_Castracani_38.pdf

Centner, R. (2003, 16 de agosto). Space and place in the new economy an after. The habitus of the hipster in millennial San Francisco. American Sociological Association. Annual Meetings, Atlanta, Georgia. https://convention2.allacademic. com/one/asa/asa/index.php?cmd=Download+Document\&key=unpublished_ manuscript\&file_index=22\&pop_up=true\&no_click_key=true\&attachment_ style=attachment\&PHPSESSID=6je2jfl6rjk7jj7hac1ncbfgli

Centner, R. (2006, 10 de agosto). Spatial capital: The power to take place. American Sociological Association, $101^{\text {st }}$ Annual Meeting. Montréal, Canada.

Centner, R. (2008). Places of privileged consumption practices: spatial capital, the dot-com habitus, and San Francisco's internet boom. City and Community, 7(3), 193-223. https://doi.org/10.1111/j.1540-6040.2008.00258.x

Cohen, A. (2019). Slavery hasn't ended, it has just become modernized. Border imperialism and the lived realities of migrant farmworkers in British Columbia, Canada. International Journal for Critical Geographies, 18(1), 130-148. https://acme-journal.org/index.php/acme/article/view/1430

Cohen, A. \& Caxaj, S. (2018). Bodies and borders: migrant women farmworkers and the struggle for sexual and reproductive justice in British Columbia, Canada. Alternate Routes: A Journal of Critical Social Research, 29, 90-117. http:/ /www.alternateroutes.ca/index.php/ar/article/view/22448

De Vito, C. G. \& Lichtenstein, A. (2016). Writing a global history of convict labour. International Review of Social History, 58(2), 285-325. https://doi.org/10.1017/ S0020859012000818 
De Vito, C. G. \& Sundevall, F. (2017). Free and unfree labour. An introduction to this special issue. Arbetarhistoria, (3-4), 6-12. https://www.arbetarhistoria.se/fulltext/introduction-163-164.pdf

Encalada, E. (2005). Harvesting seeds of justice the plight of migrant farm workers in Ontario. Women E Enviroments International Magazine, (68/69), 16-19. http:// www.yorku.ca/weimag/BACKISSUES/images/WEI\% 20scan \% 202005\% 20 iss\%2068-69\%20part1_\%202.pdf

Engerman, S. (2000). Slavery at different times and places. American Historical Review, 105(2), 480-484. https://doi.org/10.1086/ahr/105.2.480

Fogle, N. (2009). Social space and physical space: Pierre Bourdieu's field theory as a model for the social dynamics of the built environment. A dissertation (tesis doctoral). The Temple University. Filadelfia. Fil., EuA. https://digital.library.temple.edu/digital/ collection/p245801coll10/id/40829/

Foucault, M. (1979). Microfísica del poder. La Piqueta.

Gibb, H. (2006). Los trabajadores agrícolas de tierras lejanas. Resultados de un estudio internacional sobre los trabajadores agrícolas temporales de México y el Caribe que trabajan en las granjas de Ontario. Canada: The North-South Institute. http://www.nsi-ins.ca/wp-content/uploads/2012/10/2006-Farmworkers-from-Afar-SPANISH-VERSION.pdf

Giddens, A. (2006). La constitución de la sociedad. Bases para la teoría de la estructuración. Amorrortu.

Giménez, G. (2005). Introducción a la sociología de Bourdieu. En I. Jiménez (Coord.), Ensayos sobre Pierre Bourdieu y su obra (pp. 79-90). UnAm/Plaza y Valdés.

Goldring, L. \& Landolt, P. (2015). Atrapados en la matriz de trabajo y ciudadanía. Los efectos duraderos del estatus legal precario en el trabajo de los inmigrantes en Toronto. En S. M. Lara Flores, J. Pantaleón \& M. J. Sánchez Gómez (Coords.), Hacia el otro norte. Mexicanos en Canadá (pp. 43-73). Université de Montréal/Clacso.

Henestroza, M. (2003). Relaciones México-Canadá en cuanto al Programa de Trabajadores Agrícolas Temporales (PTAT). Análisis de los últimos años (1999-2002) (tesis de licenciatura). UNAM-ENEP Acatlán, México.

Hennebry, J. L. \& Preibisch, K. (2010). A model for managed migration? Re-examining best practices in Canada's Seasonal Agricultural Worker Program. International Migration, 50(1), 2-33. https://doi.org/10.1111/j.1468-2435.2009.00598.x

Kaufmann, V., Bergman, M. \& Joye, D. (2004). Motility: mobility as capital. International Journal of Urban and Regional Research, 28(4), 745-756. https://doi.org/10.1111/ j.0309-1317.2004.00549.x

Lebaron, G. (2015). Unfree labour beyond binaries. Insecurity, social hierarchy and labour market restructuring. International Feminist Journal of Politics, 17(1), 1-19. https://doi.org/10.1080/14616742.2013.813160

Lévy, J. (1994). L'espace légitime. Sur la dimension géographique de la fonction politique. Presses de la fondation nationale des sciences politiques.

Lévy, J. (2002). Sur les conditions d'habitabilité de l'espace. Annales de Géographie, 111(626), 395-405. https://www.persee.fr/doc/geo_0003-4010_2002_ num_111_626_1983

Lévy, J. \& Lussault, M. (2003). Dictionnaire de la géographie et de l'espace des sociétés. Belin. 
Márquez, H. (2012). El mundo al revés. La migración como fuente de desarrollo. Miguel Ángel Porrúa/RIMD/UAz.

Marshall, T. H. (1997). Ciudadanía y clase social. REIS, (79), 297-346. https://dialnet. unirioja.es/servlet/articulo?codigo $=760109$

Marx, C. (1973). El capital. Tomo I. FCE.

McGrath, S. (2005). Unfree labor, capitalism and contemporary forms of slavery. Graduate Faculty of political and Social Science. New School University. http://www.peri. umass.edu/fileadmin/pdf/UM-NS_Workshop/SiobhanMcGrath.pdf

Montoya, I. (2005). Programa de trabajadores agrícolas mexicanos de temporada en Canadá: Funcionamiento e implicaciones de un mercado laboral agrícola estacional (tesis de maestría). Flacso. México. http://conocimientoabierto.flacso.edu.mx/tesis/112

Muir, G. (2015). Descifrar los espacios de exclusión. El control de la migración y el reclutamiento de trabajadores guatemaltecos en Canadá a través del Programa de Trabajadores Temporales Extranjeros. En J. Sánchez \& S. Lara (Coords.), Los programas de trabajadores agrícolas temporales. ¿Una solución a los retos de las migraciones en la globalización? (pp. 57-80). UNAM. http://ru.iis.sociales.unam.mx/ jspui/bitstream/IIS/5229/1/progr_trabaj_agricolas.pdf

Naciones Unidas (ONu). (1948). La Declaración Universal de los Derechos Humanos. https://www.un.org/es/universal-declaration-human-rights/

Naciones Unidas (ONU). (1956). Convención suplementaria sobre la abolición de la esclavitud, la trata de esclavos y las instituciones y prácticas análogas a la esclavitud. https:/ / www.ohchr.org/SP/ProfessionalInterest/Pages/SupplementaryConventionAbolitionOfSlavery.aspx

Naciones Unidas (ONU). (1966). Pacto Internacional de Derechos Económicos, Sociales y Culturales. https://www.ohchr.org/SP/ProfessionalInterest/Pages/CESCR.aspx

Oficina del Alto Comisionado de las Naciones Unidas para los Derechos Humanos (OACDH). (1926). Convención sobre la Esclavitud. Consejo de la Sociedad de las Naciones. https://www.ohchr.org/SP/ProfessionalInterest/Pages/SlaveryConvention.aspx

Oficina del Alto Comisionado de las Naciones Unidas para los Derechos Humanos (OACDH). (2005). Observación general No. 18: El derecho al trabajo. https:// www.escr-net.org/es/recursos/observacion-general-no-18-derecho-al-trabajo

Organización Internacional del Trabajo (ОIт). (1957). Convenio sobre la abolición del trabajo forzoso. https://www.ilo.org/dyn/normlex/es/f?p=NORMLEXPUB:12100:0::NO::P12100_ILO_CODE:C105

Perry, J. A. (2018). Living at work and intra-worker sociality among migrant farm workers in Canada. Journal of International Migration and Integration, 19(4), 10211036. https://doi.org/10.1007/s12134-018-0583-z

Perry, J. A. (2019). Images of work, images of defiance: engaging migrant farm worker voice through community-based arts. Agriculture and Human Values, 36(3), 627640. https://doi.org/10.1007/s10460-018-9861-9

Preibisch, K. (2004a). Social relations practices between seasonal agricultural workers, their employers, and the residents of rural Ontario. The North-South Institute.

Preibisch, K. (2004b). Migrant agricultural workers and process of social inclusion in rural Canada: Encuentros and Desencuentros. Canadian Journal of Latin American and Caribbean Studies, 29(57-58), 203-239. https://doi.org/10.1080/082636 63.2004.10816857 
Preibisch, K. (2007). Local produce, foreign labor: labor mobility programs and global trade competitiveness in Canada. Rural Sociology, 72(3), 418-449. https:// onlinelibrary.wiley.com/doi/epdf/10.1526/003601107781799308

Preibisch, K. (2015). Los trabajadores migrantes y los cambios en los regímenes laborales en la producción agrícola contemporánea de Canadá. En S. M. Lara Flores, J. Pantaleón \& M. J. Sánchez Gómez (Coords.), Hacia el otro norte. Mexicanos en Canadá (pp. 115-138). Université de Montréal/Clacso. http://biblioteca. clacso.edu.ar/clacso/se/20150312050236/HaciaElOtroNorte.pdf

Preibisch, K. \& Binford, L. (2008). Interrogating racialized global labour supply: an exploration of the racial/national replacement of foreign agricultural workers in Canada. Canadian Review of Sociology, 44(1), 5-36. https:/ / onlinelibrary.wiley. com/doi/abs/10.1111/j.1755-618X.2007.tb01146.x

Rérat, P. (2018). Spatial capital and planetary gentrification: residential location, mobility and social inequalities. En L. Lees \& M. Phillips (Coords.), Handbook of Gentrification Studies (pp. 103-118). Edward Elgar Publishing.

Rérat, P. \& Lees, L. (2011). Spatial capital, gentrification, and mobility: evidence from Swiss core cities. Transactions, (36), 126-142. https://www.suz.uzh.ch/dam/ jcr:00000000-68cb-72db-0000-00005a3c8fe0/05.07_rerat_lees_11.pdf

Ritzer, G. (2002). Teoría sociologica contemporánea. McGraw-Hill.

Satzewich, V. (1991). Racism and the incorporation of foreign labour: Farm labour migration to Canada since 1945. Routledge.

Scott, J. (2011). Los dominados y el arte de la resistencia. ERA.

Sharma, N. (1995). The true north strong and unfree: capitalist restructuring and non-immigrant employment in Canada, 1973-1993 (tesis de maestría). Simon Fraser University. Canadá.

Sharma, N. (2000). Race, class, gender, and the making of difference: the social organization of migrant workers in Canada. Atlantis: Critical Studies in Gender, Culture y Social Justice, 24(2), 5-15. https://journals.msvu.ca/index.php/atlantis/ article/view/1584

Sharma, N. (2001). On being not Canadian: The social organization of migrant workers in Canada. The Canadian Review of Sociology and Anthropology, 38(4), 415-439. https://onlinelibrary.wiley.com/doi/abs/10.1111/j.1755-618X.2001.tb00980.x

Silva, R. (2014). La suerte de un clásico: el caso de Thomas Humphrey Marshall. Revista CS, (13), 361-386. https://doi.org/10.18046/recs.i13.1831

Silverman, S. \& Hari, A. (2016). Troubling the fields: choice, consent, and coercion of Canada's seasonal agricultural workers. International Migration, 54(5), 91-104. https://doi.org/10.1111/imig.12266

Strauss, K. (2012). Coerced, forced and unfree labour: geographies of exploitation in contemporary labour markets. Geography Compass, 6(3), 137-148. https://doi. org/10.1111/j.1749-8198.2011.00474.x

Strauss, K. (2014). Le travail non libre dans les économies contemporaines. Revue Droits et Libertés, 33(2), 1-4. https://liguedesdroits.ca/le-travail-non-libre-dansles-economies-contemporaines/

Strauss, K. \& McGrath, S. (2017). Temporary migration, precarious employment and unfree labour relations: Exploring the "continuum of exploitation" in Canada's Temporary Foreign Worker Program. Geoforum, 78, 199-208. https://doi. org/10.1016/j.geoforum.2016.01.008 
Vanegas, R. (2000a). Un mosaico multiétnico: la política migratoria en Canadá. En T. Gutiérrez-Haces (Coord.), Canadá: un Estado Posmoderno (pp. 311-326). Plaza y Valdés.

Vanegas, R. (2000b). Pacto de Caballeros: Programa de Trabajadores Agrícolas Mexicanos Temporales en Canadá (ponencia). Seminario Permanente de Estudios Chicanos y de Fronteras, DEAS-INAH. México.

Vargas-Foronda, J. (2010). El Programa de Trabajo Agrícola Temporal en Canadá en su vir aniversario 2003-2010. Una hipócrita negociación: Exportamos mano de obra barata con enormes rendimientos y altos lucros. Su cruda perversión y magnificada degradación. Flacso. https://www.academia.edu/41269963/ PTAT_Canad\%C3\%A1_II_Ver_Revisada

Verduzco, G. (2000). El programa de trabajadores agrícolas mexicanos con Canadá: Aprendizaje de una nueva experiencia. En T. Gutiérrez-Haces (Coord.), Canadá: un Estado Posmoderno (pp. 327-346). Plaza y Valdés.

Verduzco, G. (2015). El PтAт y los programas de trabajadores temporales. Una visión crítica. En S. M. Lara Flores, J. Pantaleón \& M. J. Sánchez Gómez (Coords.), Hacia el otro norte. Mexicanos en Canadá (pp. 89-114). Université de Montréal/Clacso.

Weber, M. (1964). Economía y sociedad. FCE.

Iván Montoya Zepeda

Mexicano. Maestro en estudios de población por la Facultad Latinoamericana de Ciencias Sociales, México. Estudiante del doctorado en geografía de la Universidad Nacional Autónoma de México (unAM). Profesor investigador en la Universidad Autónoma Metropolitana, Azcapotzalco. Líneas de investigación: Migración laboral, relaciones socioespaciales y género, trayectorias estudiantiles en la educación superior. Publicación reciente: De Garay, A., Miller, D. \& Montoya, I. (2017). Las trayectorias escolares universitarias en un tablero de serpientes y escaleras. ANUIEs. 